\title{
Laboratory Investigation of Detopping Unit for Mini-tractor Operated Harvester for Small Onion (Allium Cepa var. Aggregatum)
}

\author{
R. Sai Prasanth ${ }^{1 *}$, P. K. Padmanathan ${ }^{1}$, S. S. Sivakumar ${ }^{1}$ and V. Alex Albert ${ }^{2}$ \\ ${ }^{1}$ Department of Farm Machinery and Power Engineering, ${ }^{2}$ Department of Basic Engineering \\ and Applied Sciences, AEC \& RI, Kumulur, India \\ *Corresponding author
}

\section{Keywords}

Detopping, Onion harvester, Onion neck length, RSM methodology

Article Info

Accepted:

24 October 2020

Available Online:

10 November 2020

\begin{abstract}
A B S T R A C T
In India, detopping of onion is carried out mostly by manual operation after uprooting of the onions which is tedious and time consuming. In this study, laboratory evaluation of mechanized detopping unit was demonstrated before uprooting the onions. The crop was grown in plastic trays with spacing of $20 \mathrm{x} 12 \mathrm{~cm}$. The detopping unit consists of vertical shaft attached with cutting thread at the bottom end. Reinforced composite nylon material was chosen as cutting material due to its extra strength and high resistance to breakage. The nylon thread detops the onion leaves in rotary cutting as line trimmers. Based on the cross sectional area, three different types of threads (square $-\mathrm{T}_{1}$, round $-\mathrm{T}_{2}$ and flat with one side serrated $-\mathrm{T}_{3}$ ) were selected for evaluation of detopping unit. The detopping unit was evaluated at three levels of peripheral speed $\left(5.31-\mathrm{N}_{1}, 6.64-\mathrm{N}_{2}\right.$ and $7.97 \mathrm{~m} \mathrm{~s}^{-1}-\mathrm{N}_{3}$ ) of the unit, and three forward speeds $\left(1-\mathrm{S}_{1}, 1.5-\mathrm{S}_{2}\right.$ and $\left.3.4 \mathrm{kmph}-\mathrm{S}_{3}\right)$ using sticky belt. The better performance of detopping onion was observed in square shaped cross-sectional type $\left(\mathrm{T}_{1}\right)$ nylon string with both four strings and eight strings $\left(\mathrm{H}_{2}\right.$ and $\left.\mathrm{H}_{3}\right)$ for the average onion neck length of $23 \mathrm{~mm}$ and it was sufficient for minimising storage losses of onions. The optimum peripheral speed of detopping unit was observed as $6.64 \mathrm{~m} \mathrm{~s}^{-1}$ with forward speed of $1 \mathrm{kmph}$.
\end{abstract}

\section{Introduction}

Onion (Allium Cepa var.) is the second most important vegetable crop in the world. It is a native crop of Asia and was introduced in India by Palestine. As it is one of the basic indispensable vegetables, the demand for onion bulbs has remained fairly consistent irrespective of wide fluctuations in the market prices. India is the leading exporter of fresh onions, $1.902 \mathrm{MT}$ of onions were exported in 2018-19. According to Ministry of
Agriculture, for the year 2017-18 the area of onion cultivation is $1.284 \mathrm{M}$ ha with 23.26 MT productions.

The area of onion cultivation in the state of Tamilnadu is 28,360 ha with production of 0.301 MT in 2017-18. The other major states that are producing onions in the country are Maharashtra, Gujarat, Karnataka, Uttar Pradesh, Andhra Pradesh, Orissa, Madhya Pradesh, Rajasthan and Bihar. 
The harvesting of onions includes digging the onions from the soil, lifting them by the elevators, conveying, field curing for 3-5 days, cutting the necks to separate onions from the foliage (detopping). The most of the onion harvesters involves only operation like digging the onions and conveying them to the field by elevators. After field curing, traditional detopping was done by removing the leaves from the onions with the help of cutting tools like sickle, thread cutter scissors manually. Detopping of the onions is the most tedious, laborious and time consuming operation and demands huge labour to the extent of 12.5 man-hrs for 1 MT of onion bulbs (Raniand Srivatsava, 2012).

The power operated detoppers were used for mechanical detopping of onions. Various researchers have developed a separate stationary power operated detoppers in past. Rani and Srivastava (2012) developed an onion detopper consists of chute for feeding the onions along with leaves, belt conveyer to give forward movement to the onions, and oscillating conveyer to convey the onions to the rotary blade. The rotary blade detops the onion at rotational speed of $1000 \mathrm{rpm}$ and capacity of $300 \mathrm{~kg} / \mathrm{h}$ and onion neck length after detopping as $22 \mathrm{~mm}$. Bhanage (2015) developed a power operated onion de-topper that consists of two spiral rollers which was key component of machine. The cutting unit consisted of shaft, two plain and one serrated cutter. Field performance of developed power operated onion detopper indicated that the maximum detopping efficiency of $86.63 \%$ with output capacity of $315 \mathrm{~kg} / \mathrm{h}$. Onion neck length of $21.09 \mathrm{~mm}$ was found after detopping operation which was sufficient for storage losses of onions. Traditional detopping capacity was $80 \mathrm{~kg} / \mathrm{h}$ and Rs.28.12 per quintal and with power operated detopper was Rs.18.84 per quintal. There was savings of Rs.9.28 per quintal
Chittappa(2016) developed a power operated onion detopper cum grader consisting of feed chute to feed the cured onion crop for detopping. Onion detopper was integrated with expanding open type grader that attached electric motor. The performance of the machine was found to be $90.58 \%$ detopping efficiency and $83.56 \%$ grading efficiency with a damage of $8.68 \%$.

Randal and Nulty (1978) studied the impact cutting behavior of forage crops by doing field tests and reported that the energy balance is a function of both cutting speed and the forward speed. The work per unit area was decreasing as forward velocity was increasing from 2 to $9 \mathrm{kmph}$.

Detopping of onion before uprooting the crop from the soil is conceived for mechanization of the onion crop for easy handling and reducing the labour cost. When detopping is done before uprooting the onions, the crop is stationary and the unit is in moving condition. Hence, the parameters that should be considered for the performance evaluation of detopping unit are forward speed of the unit, peripheral speed of detopping unit and type of the material that cuts the onion leaves.

\section{Materials and Methods}

In order to investigate the performance of detopping unit, a laboratory setup was developed for detopping the onions before uprooting. The major components of the test rig were detopping unit, sticky belt, AC motor and variable speed drive.

\section{Detopping unit}

The detopping unit was designed for cutting the onion leaves by rotary impact cutting method (Dauda et al., 2015). It consists of detopping thread fixed in horizontal plane to a $10 \mathrm{~mm}$ vertical rod at a distance of $5 \mathrm{~mm}$ from 
the bottom. To adjust the depth of cut up to 50 $\mathrm{mm}$, slots were provided at $10 \mathrm{~mm}$ interval in the vertical rod. Two trapezoidal frames were fabricated using L-angles for mounting the detopping unit and a $3 \mathrm{hp}$ electric motor to operate the detopping unit. Supports were provided on both the trapezoidal frame using flats to arrest the lateral movement of the main frame. The overall dimensions of the main frame were $100 \times 100 \mathrm{~cm}$ at base, $60 \mathrm{x}$ $60 \mathrm{~cm}$ at top and $100 \mathrm{~cm}$ height. A variable speed drive was connected to the motor for altering the peripheral speed of cutting.

The cutting energy required for cutting stalks shows a negative correlation with weight of cutting material (Yiljep and Mohammed, 2005). Hence, reinforced composite nylon material was chosen as material of thread due to its extra strength and its resistance to breakage. Three different cross sectional types of nylon strings have been chosen for the evaluation. They are square $\left(\mathrm{T}_{1}\right)$, round $\left(\mathrm{T}_{2}\right)$ and one side serrated and other with flat surface $\left(\mathrm{T}_{3}\right)$ having thickness of $3.5 \mathrm{~mm}, 3.5$ $\mathrm{mm}$ and $2.5 \mathrm{~mm}$ respectively. For the optimization of better nylon string three types of string arrangement was chosen viz., two, four and eight cutting strings $\left(\mathrm{H}_{1}, \mathrm{H}_{2}\right.$ and $\left.\mathrm{H}_{3}\right)$. The details were shown in following figure 1.

The values of peripheral speed of the nylon string were chosen based on the speed at which the cutting of leaves were started i.e., $5.05 \mathrm{~ms}^{-1}$ (950rpm). It was measured by using digital tachometer. Three levels were chosen from that value viz., $5.31\left(\mathrm{~N}_{1}\right), 6.65\left(\mathrm{~N}_{2}\right)$ and $7.97\left(\mathrm{~N}_{3}\right) \mathrm{ms}^{-1}$.(1000, 1250 and $\left.1500 \mathrm{rpm}\right)$.

\section{Crop variety}

The CO (On5) onion variety was selected based on its high yielding capacity and it was grown in $40 \times 30 \mathrm{~cm}$ plastic tray at a spacing of $20 \times 12 \mathrm{~cm}$ for conducting the experiments. The duration of crop was three to five months after the translpanting and the experiment was conducted at $85^{\text {th }}$ day i.e., after $50 \%$ leaves have fallen over (Kamaraj, 2002).

\section{Crop conveyor}

Plastic trays consisting of crops were placed on belt having centre to centre distance of $2.5 \mathrm{~m}$ and width $0.4 \mathrm{~m}$. It was connected to a single phase electric motor of $3 \mathrm{hp}$ and for altering the forward speed avariable speed drive was connected to the motor.

For the laboratory evaluation forward speed of tractor was considered as the forward speed of the belt. Hence, three levels were chosen by calculating the speed of mini-tractor at low first, second and third gears viz $1\left(\mathrm{~S}_{1}\right), 1.5\left(\mathrm{~S}_{2}\right)$ and $3.4\left(\mathrm{~S}_{3}\right) \mathrm{kmph}$ respectively.

The crop placed on the conveyer platform comes in contact with the nylon string of detopping unit; the leaves get separated from the bulb. The tray was collected manually at the backside of the main frame. The overall test rig arrangement is shown in fig. 2 .

\section{Onion neck length}

Onion neck length is the basic parameter considered for the evaluation of detopping unit (Rani and Srivastava, 2012; Bhanage, 2015). It is defined as the length between the onion bulb and top cut portion of the onion bulb. It is measured with the help of verinor caliper of range $0-150 \mathrm{~mm}$ with least count of $0.01 \mathrm{~mm}$.

The recommended average onion neck length after detopping the onions based on the reviews of previously developed onion detoppers as shown in table 1 was $20-25$ $\mathrm{mm}$. The effects of type of string $(\mathrm{T})$, number of strings $(\mathrm{H})$, peripheral speed of detopping unit $(\mathrm{N})$ and forward speed $(\mathrm{S})$ on the 
performance of the detopping unit was studied based on the height of cut.

The number of experiments done for the evaluation of detopping unit were $3 \times 3 \times 3 \times 3=81$ i.e., three types of threads, three types of thread arrangements, three levels of peripheral speed and three levels of forward speed with each experiment replicated three times. The data was recorded and analyzed by using AGRESS (Statistical Analysis Software).

\section{Results and Discussion}

The results obtained in the laboratory investigation were explained by the following graphs.

The fig. 3 shows the effect of peripheral speed on height of cut i.e., onion neck length after detopping using square type of thread $\left(\mathrm{T}_{1}\right)$ with two cutting strings $\left(\mathrm{H}_{1}\right)$. It was inferred that the onion neck length decreased as the peripheral speed of detopping unit is increased. At uniform forward speed as the peripheral speed increases, more number of shear cuts resulting in required uniform neck length of onion.
The increase in peripheral speed increases cutting energy. The increase in peripheral speed from 6.64 to $7.97 \mathrm{~ms}^{-1}$ has negligible effect on variation in onion neck length. This implies that increase in peripheral speed of detopping unit above $6.64 \mathrm{~ms}^{-1}$ resulting in same level of neck length and increase in specific cutting energy (Randy and Nulty, 1978; Jyothi, 2013).

The forward speed has significant effect in the varying the onion neck length. By increasing the forward speed work per unit area was decreasing and the time taken to cut the crop is reduced resulting in the change of onion neck length (Randy and Nulty, 1978; Jyothi, 2013). It was observed in the treatment $\mathrm{N}_{1}$ the onion neck length is gradually increased from $S_{1}$ to $S_{2}$ and there was a sharp rise from $S_{2}$ to $\mathrm{S}_{3}$ indicating that there was no detopping happened at $\mathrm{S}_{3}$ level. There was a similar trend observed in $\mathrm{N}_{2}$ and $\mathrm{N}_{3}$ for three levels of forward speed.

A similar trend was observed regarding forward speed and peripheral speed of the detopping unit when four and eight strings $\left(\mathrm{H}_{2}\right.$ and $\mathrm{H}_{3}$ ) (Fig. 4 and 5).

Table.1 Recommended onion neck length by previous authors

\begin{tabular}{|r|l|l|}
\hline S. No & Onion neck length & \multicolumn{1}{c|}{ Author } \\
\hline 1. & $25 \mathrm{~mm}$ & Chauhan et al. $(1995)$ \\
\hline 2. & $25 \mathrm{~mm}$ & Singhal (2000) \\
\hline 3. & $22 \mathrm{~mm}$ & Rani and Srivastava (2012) \\
\hline $\mathbf{4 .}$ & $20.66 \mathrm{~mm}$ & Bhanage (2015) \\
\hline
\end{tabular}

Table.2 Selected values of the operational parameters

\begin{tabular}{|c|c|c|c|c|}
\hline S.NO & $\begin{array}{c}\text { Shape of } \\
\text { string(T) }\end{array}$ & $\begin{array}{c}\text { No.of cutting } \\
\text { strings(H) }\end{array}$ & $\begin{array}{c}\text { Forward } \\
\text { speed(S) } \\
\text { (kmph) }\end{array}$ & $\begin{array}{c}\text { Peripheral } \\
\text { speed } \\
\left(\mathbf{m s}^{-\mathbf{1}} \mathbf{)}\right.\end{array}$ \\
\hline $\mathbf{1 .}$ & Square & Two & 1 & 5.31 \\
\hline $\mathbf{2 .}$ & Round & Four & 1.5 & 6.64 \\
\hline $\mathbf{3 .}$ & Flat with one side & Eight & 3.4 & 7.97 \\
\hline
\end{tabular}


Table.3 ANOVA for variance in onion neck length

\begin{tabular}{|l|l|l|l|l|l|l|}
\hline \multicolumn{1}{|c|}{ Source } & df & Sum of squares & \multicolumn{1}{|c|}{ Means squares } & \multicolumn{1}{c|}{ P } & \multicolumn{1}{c|}{ PROB } & \\
\hline Shape of string (T) & 2 & 2123153.896 & 1061576.948 & 756.4786 & 0.0000 & $* *$ \\
\hline Forward speed of unit (S) & 2 & 1194417.850 & 597208.925 & 425.5705 & 0.0000 & $* *$ \\
\hline $\begin{array}{l}\text { Peripheral Speed of } \\
\text { detopping unit (N) }\end{array}$ & 2 & 28285.262 & 14142.631 & 10.0780 & 0.0001 & $* *$ \\
\hline Number of strings (H) & 2 & 6183.746 & 3091.873 & 2.2033 & 0.1138 & NS \\
\hline TXH & 4 & 17336.458 & 4334.114 & 3.0885 & 0.0175 & $*$ \\
\hline TXN & 4 & 46145.793 & 11536.448 & 8.2209 & 0.0000 & $* *$ \\
\hline TXS & 4 & 690071.172 & 172517.793 & 122.9360 & 0.0000 & $* *$ \\
\hline HXN & 4 & 32625.071 & 8156.267 & 5.8121 & 0.0002 & $* *$ \\
\hline HXS & 4 & 4256.806 & 1064.201 & 0.7583 & 0.5539 & NS \\
\hline NXS & 4 & 31432.610 & 7858.152 & 5.5997 & 0.0003 & $* *$ \\
\hline TXHXN & 8 & 16620.729 & 2077.591 & 1.4805 & 0.1681 & NS \\
\hline TXHXS & 8 & 16313.775 & 2039.221 & 1.4531 & 0.1785 & NS \\
\hline TXNXS & 8 & 61365.354 & 7670.669 & 5.4661 & 0.0000 & $* *$ \\
\hline HXNXS & 8 & 34486.793 & 4310.849 & 3.0719 & 0.0030 & $* *$ \\
\hline TXHXNXS & 16 & 89457.387 & 5591.086 & 3.9842 & 0.0000 & $* *$ \\
\hline ERR & 160 & 224530.213 & 1403.313 & 1.0000 & & \\
\hline
\end{tabular}

$(* *)$ significant at 1 per cent level; $(*)$ significant at 5 per cent level; NS - non significant

Fig.1 Top view of string arrangement i.e. $\mathrm{H}_{1}, \mathrm{H}_{2}$, and $\mathrm{H}_{3}$

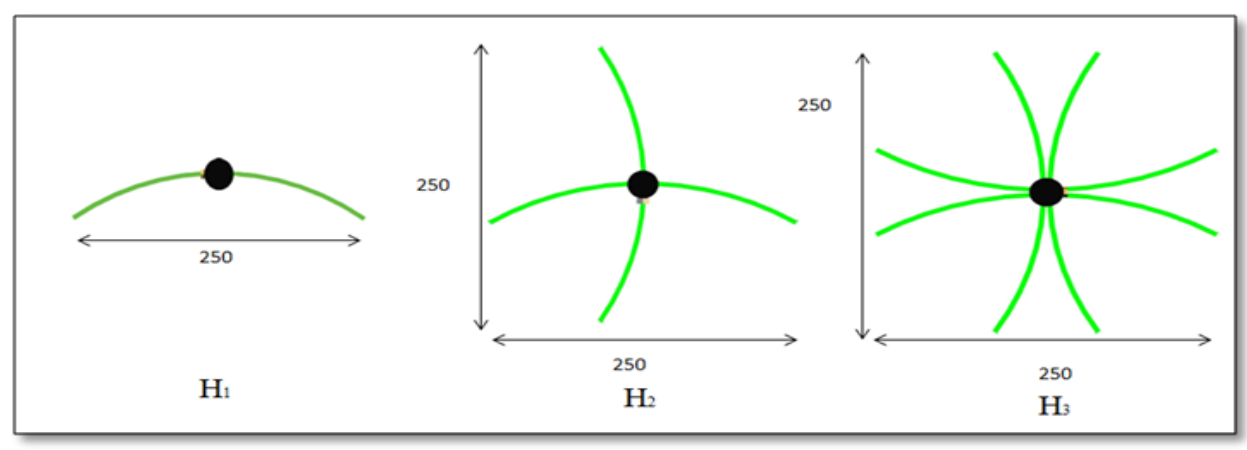

Fig.2 Laboratory setup model

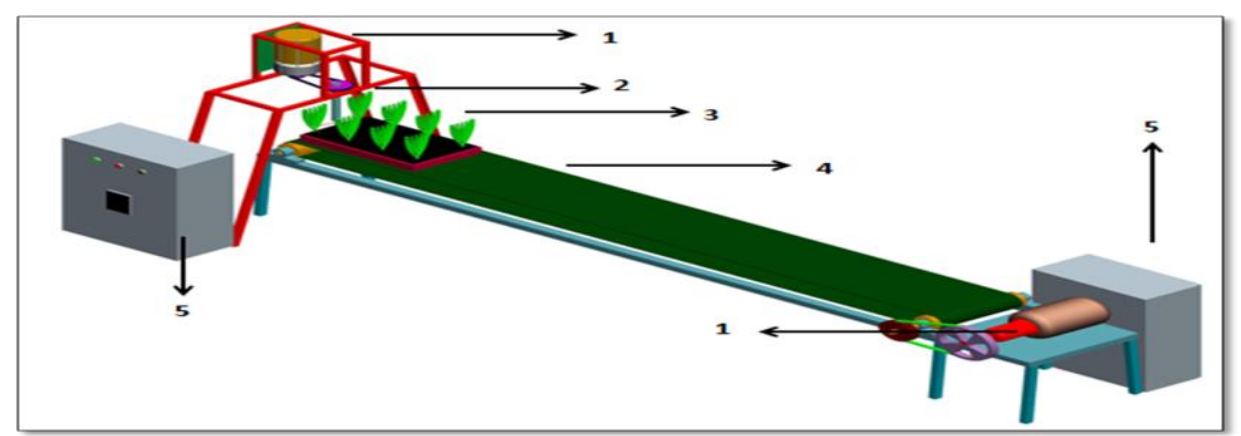

1. Single phase $3 \mathrm{hp} \mathrm{electric} \mathrm{motor} \mathrm{2.} \mathrm{Detopping} \mathrm{unit} \mathrm{3.Crop} \mathrm{samples} \mathrm{4.} \mathrm{Crop} \mathrm{conveyer}$ 5. Variable speed drive 
Fig.3 Effect of peripheral speed on height of cut at different forward speed with square type string and two cutting strings

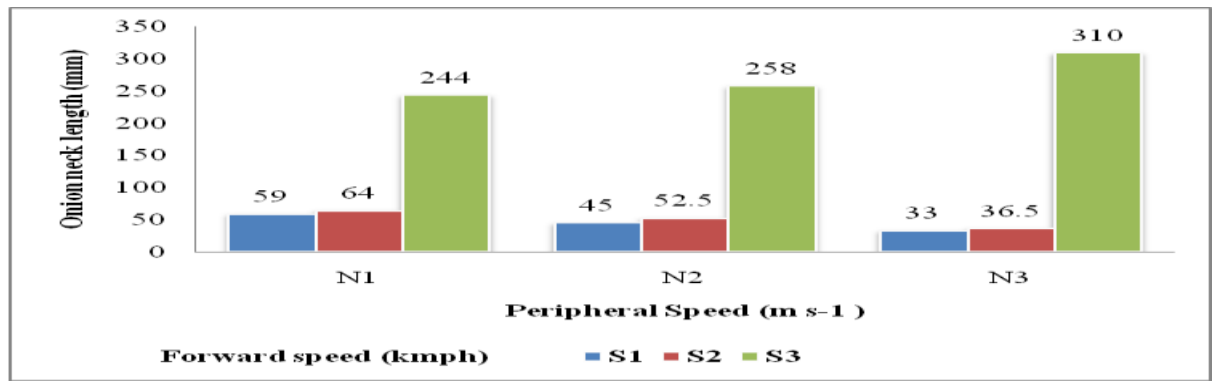

Fig.4 Effect of peripheral speed on height of cut at different forward speed with square type string and four cutting strings

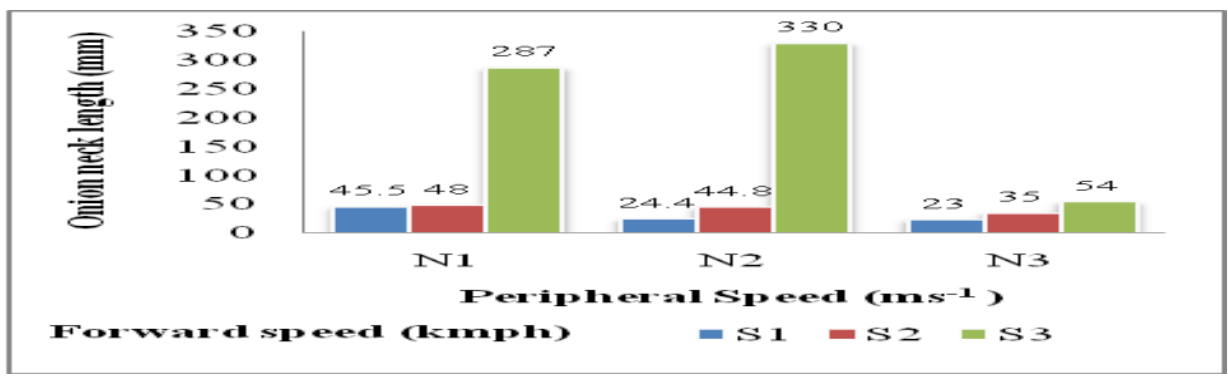

Fig.5 Effect of peripheral speed on height of cut at different forward speed with square type string is used and eight cutting strings

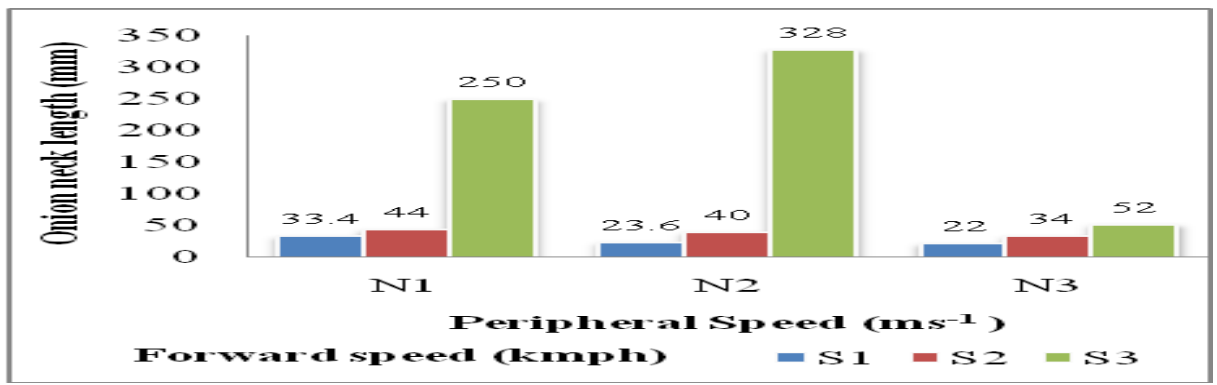

Fig.6 Effect of no. of strings on the height of cut with variation in forward speed with square type thread is used at $5.31 \mathrm{~ms}^{-1}$

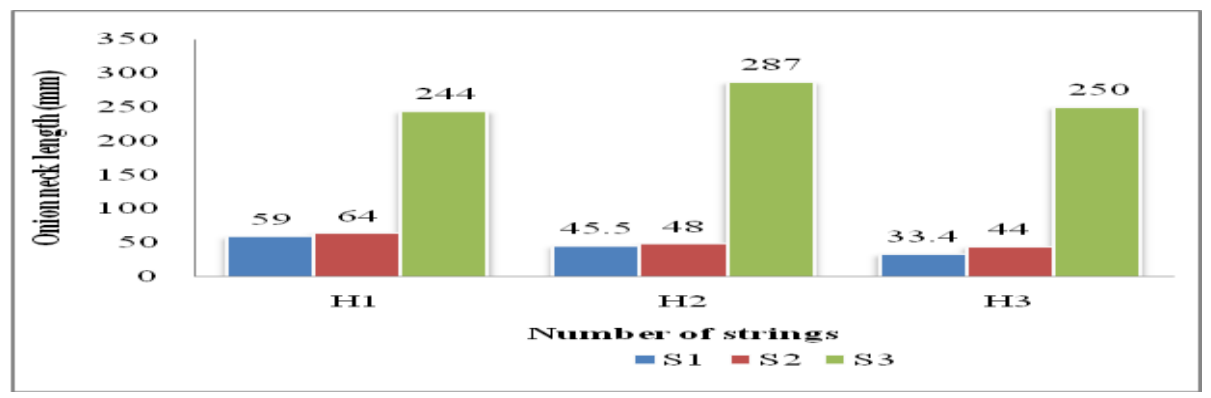


Fig.7 Effect of shape of string on height of cut at different peripheral speeds at $1 \mathrm{kmph}\left(\mathrm{S}_{1}\right)$ with two strings were used

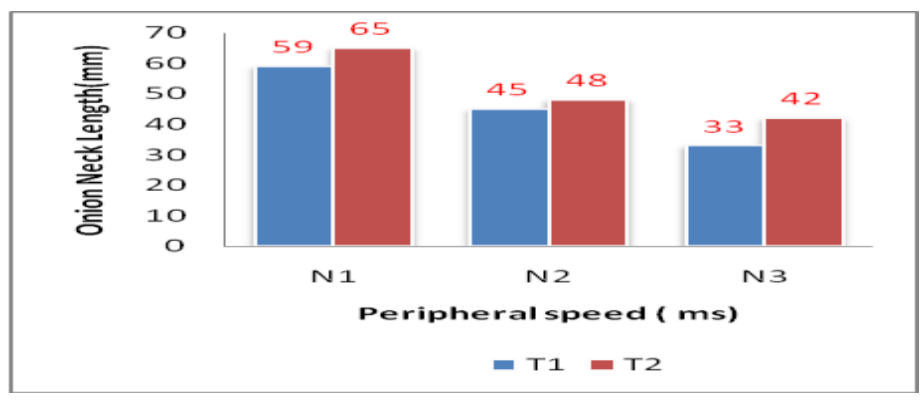

Fig.8 Effect of shape of string on height of cut at different peripheral speeds at $1 \mathrm{kmph}\left(\mathrm{S}_{1}\right)$ with four strings were used

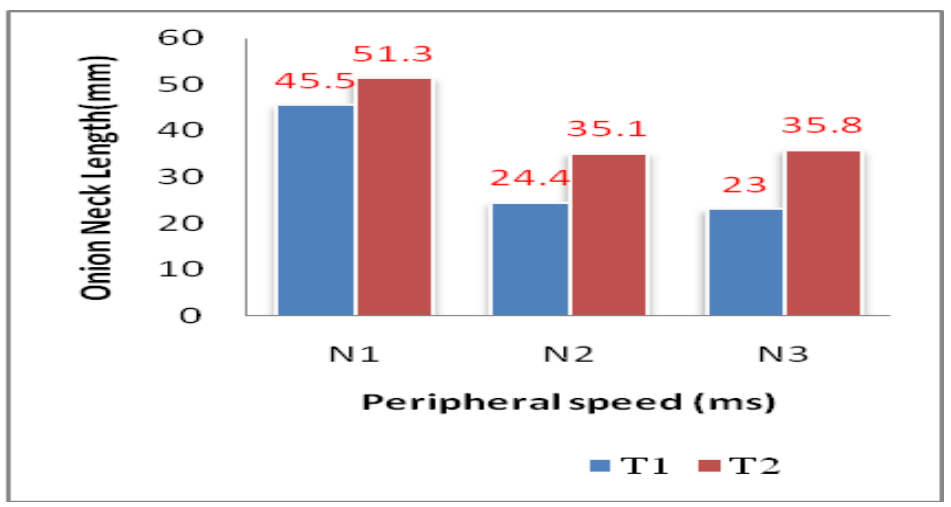

The graph in fig. 6 indicates the result of treatments when square type thread $\left(\mathrm{T}_{1}\right)$ was used at $5.31 \mathrm{~ms}^{-1}\left(\mathrm{~N}_{1}\right)$ by varying the number of cutting strings with forward speed of the unit. As the number of cutting strings increases number of cuts per unit time on the onion leaves increases it affects the change in onion neck length. The onion neck length decreased from $\mathrm{H}_{1}$ to $\mathrm{H}_{3}$. In the treatments $S_{1}$ and $S_{2}$ the onion neck length is gradually decreased. In treatment $S_{3}$ the value of onion neck length is high indicating that there was no detopping.

By comparing Fig.7 and Fig 8 indicating the effect of shape of thread on the onion neck length at different levels of peripheral speed it was inferred that after detopping the value of neck length is less in square type thread $\left(T_{1}\right)$ because of its sharp edge when compared with round type thread $\left(\mathrm{T}_{2}\right)$. The values of flat type of thread with serrations on one side (T3) were neglected as there was no appreciable cut done at all levels of forward speed, peripheral speed and number of strings because of its thickness.

From table 3, the individual operational parameters shape of string $(\mathrm{T})$, forward speed of the unit (S), and peripheral speed $(\mathrm{N})$ were significantly affecting the height of cut $(\mathrm{mm})$ at 1 per cent significant effect. In addition to this the interaction effects of the pairs shape of thread with peripheral speed and forward speed were significant at 1 per cent and with number of strings at 5 per cent. Similarly, the shape of string is significant with interactions of number of strings and forward speed, peripheral speed and forward speed were also significant at 1 per cent.

The interaction effects of peripheral speed with number of strings and forward speed were significant at 1 per cent and the effect with combination of these three factors was also significant at 1 per cent. But the parameter number of strings $(\mathrm{H})$ individually does not have any significant effect in varying onion neck length 
$(\mathrm{mm})$. The interaction effect of it with shape of string has a significant effect of 5 per cent whereas, with forward speed was not significant. The combination effect of shape of string number of strings and peripheral speed was not significant. $\mathrm{T} X \mathrm{H} \times \mathrm{N} \times \mathrm{S}$ was significant affecting the height of cut $(\mathrm{mm})$ at 1 percent significant. This shows that the different levels of operational parameters have effect on height of cut either individual or combine. Though number of strings $(\mathrm{H})$ is non-significant individually for height of cut but it has significant effect in combination with shape of thread $(\mathrm{T})$.

In conclusion the required de-topping neck length of onions was observed in square shaped crosssectional type nylon string $\left(\mathrm{T}_{1}\right)$ with average onion neck length of $23 \mathrm{~mm}$ that is sufficient for reducing storage losses of onions. As the number of strings increased from two to four there was reduction in onion neck length but from four to eight strings there was negligible change in the length. This parameter is non-significant individually when it was analyzed statistically. Since there was no appreciable effect in onion neck length by altering the peripheral speed of from $6.64 \mathrm{~ms}^{-1}$ to $7.97 \mathrm{~ms}^{-1}$. It is better to operate the unit at lowest peripheral speed i.e., at $6.64 \mathrm{~ms}$ 1 and forward speed as $1 \mathrm{kmph}$ to get the recommended onion neck length.

\section{References}

Bhanage, G. B. 2012. Development and performance evaluation of power operated onion detopper. Published M. Tech thesis M. P. K. V. Rahuri.

Chittappa B. 2016.Design and Development of motorized onion detopper cum grader. http://krishikosh.egranth.ac.in/handle/1/5810 041558 Published M.Tech thesis U.A.S. Bengaluru
Chauhan, K.P.S., S.P. Singh. and Chougule, A.B. 1995, Studies on the effect of windrow curing, neck cut and shade curing on export quality of onion bulbs during storage. National Horticultural Research and Development Foundation Newsletter, 15(4): 5-7

Dauda, S.M., Ahmad, D., Khalina, A., and Jamarei, O. 2015, Effect of cutting speed on cutting torque and cutting power of varying kenaf stem diameters at different moisture contents. Tropical Agricultural Science, 38(4):549-561.

Jyothi, B. 2013 Development and evaluation of cassava stem harvester as influenced by machine and operational parameters. Unpublished M.Tech thesis TNAU, Coimbatore.

Kamaraj, P. 2002. Design, Development and evaluation of self propelled onion digger. Published M. Tech thesis TNAU Coimbatore.

Mcrandal, D. M., and P. B. Mcnulty. 1978. "Cutting Behaviour of Forage Crops." The British Society of Research in Agricultural Engineering 23(8634):329-38.

Singhal, S.C. 2000. Export of onion - Challenges and strategies. Souvenir, National Symposium on Onion and Garlic Production and Post-harvest Technology Management.

Vijaya Rani and Srivastava, A. R. 2006. Physical and Mechanical Properties of Onion (Allium Cepa L.) Crop Relevant to Mechanical Detopping, Journal of Agricultural Engineering Vol. 43(3): 83-84

Yiljep, Y. D., and U. S. Mohammed. 2005. "Effect of Knife Velocity on Cutting Energy and Efficiency during Impact Cutting of Sorghum Stalk." Agricultural Engineering International: The CIGR EJournal, VII(004):1-10.

\section{How to cite this article:}

Sai Prasanth, R., P. K. Padmanathan, S. S. Sivakumar and Alex Albert, V. 2020. Laboratory Investigation of Detopping Unit for Mini-tractor Operated Harvester for Small Onion (Allium Cepa var. Aggregatum). Int.J.Curr.Microbiol.App.Sci. 9(11): 3638-3645.

doi: https://doi.org/10.20546/ijcmas.2020.911.436 